\title{
Lip Cavernous Hemangioma in a Young Child
}

\author{
Érica Dorigatti de AVILA \\ Rafael Scaf de MOLON \\ Nicolau CONTE NETO \\ Marisa Aparecida Cabrini GABRIELLI \\ Eduardo HOCHULI-VIEIRA
}

Department of Diagnosis and Surgery, Araraquara Dental School, São Paulo State University, Araraquara SP, Brazil

\begin{abstract}
Hemangiomas are benign tumors of infancy and childhood, characterized by a phase of fast growth with endothelial cell proliferation, occurring in $10-12 \%$ of children at 1 year of age. It is known that hemangiomas of infancy are most commonly located on the head and neck region (around $60 \%$ of cases) and occur more frequently in the lips, tongue, and palate. Approximately 50\% of hemangiomas have complete resolution, and $90 \%$ of them are resolved up to the age of 9 . Complications occur in only $20 \%$ of the cases, the most common problem being ulceration with or without infection. The treatment depends on lesion location, size and evolution stage, and the patient's age. Surgery is usually indicated when there is no response to systemic treatments, or even for esthetic reasons, being performed as a simple excision in combination or not with plastic surgery. This paper reports a case of lip cavernous hemangioma in a 4-year-old child, who was submitted to 3 sessions of vascular sclerosis due to the size of the lesion, before undergoing simple excision of the hemangioma. Two years of postoperative clinical follow-up shows treatment success with no recurrence of the lesion.
\end{abstract}

Key Words: Hemangioma, intramuscular hemangioma, cavernous hemangioma.

\section{INTRODUCTION}

Hemangioma is the most ordinary benign tumor of vascular origin, occurring most frequently in newborns and during infancy and childhood, although some cases develop in adults (1). It affects approximately $10-12 \%$ of children at 1 year of age, and up to $30 \%$ of those weighing up to $1,000 \mathrm{~g}$ at birth $(2,3)$. Historically, hemangiomas have been classified in a variety of ways. An important descriptive classification is related to the depth of soft tissue involvement: superficial, deep, and mixed (4).

The term cavernous hemangioma has traditionally been applied when lesional vascular channels are considerably enlarged. It presents some similar clinical characteristics to capillary hemangioma, as predilection for females and region of head and neck region, and the greater incidence in infancy (5). The large forms of infantile cavernous hemangiomas frequently have accelerated growth and may cause significant functional disturbances and existential complications (6).

Hemangiomas show a notorious higher prevalence in females (3:1 to 7:1 predilection). The head and neck region is more commonly affected, especially the face, oral mucosa, lips, tongue and trunk. Size can vary from few millimeters to several centimeters $\left(0.25\right.$ to $\left.200 \mathrm{~cm}^{3}\right)$. The skin is the organ of most frequent occurrence (7).

The lesions are clinically observed as an anemic spot, at times erythematous, or as small cluster of deep red papulae (8). They usually have their initiation with a rapid growth stage, and approximately $90 \%$ of the cases become evident at the end of the first month of life. Then, a stagnation stage is initiated and continues for several months. After this stage, they involute slowly showing a regression rate of $90 \%$ up to 10 years of age. Occasionally, hemangiomas may appear in a late form, especially those lesions located in deeper planes $(8,9)$.

There is yet no consensus on the physiopathology of hemangiomas. Its appearance is attributed to genetic and cellular factors, mainly to monocytes, which are considered the potential ancestors of hemangioma endothelial cells (10). It is believed that these lesions result from an unbalance in the angiogenesis, which causes an uncontrolled proliferation of vascular elements (9), associated with substances such as vascular endothelial

Correspondence: Prof. Dr. Eduardo Hochuli Vieira, Departamento de Diagnóstico e Cirurgia, Faculdade de Odontologia de Araraquara, UNESP; Rua Humaitá, 1680, 14801-903 Araraquara, SP, Brasil. Tel: +55-16-3301-6359. Fax: +55-16-3301-6369. e-mail: hochuli@foar.unesp.br 
growth factor (VEGF), basic fibroblast growth factor (BFGF) and indoleamine 2,3-dioxygenase (IDO), which are found in large amount during proliferative stages, although reduced throughout involution stage $(6,11)$.

Differential diagnosis between vascular and nonvascular lesions is based on clinical findings and semiotic maneuvers, such as diascopy or glass-slide pressure $(2,9)$. Imaging resources can also be useful in both diagnostic differentiation and analysis of lesion features with regard to its size, extension and location, as well as for follow up of lesions treated under a systemic therapy (9).

It is estimated that $10-20 \%$ of hemangiomas need treatment, especially those causing complications like congestive heart failure, hypothyroidism, visual, respiratory and auditory impairment, and deformities $(7,8)$.

Systemic corticosteroid has been established as the most efficient medical therapy for common cutaneous infantile hemangiomas if started early in the proliferative phase. A 7-month-old girl with a craniofacial cavernous hemangioma has been successfully treated with oral methylprednisolone (12), showing that oral steroid treatment is an efficient medical therapy for common cavernous infantile hemangiomas with accelerated growth if started early in the proliferative phase. However, the choice of therapy in hemangiomas depends of the anatomic location, accelerating growth, significant functional disturbances and unaesthetic markings (6).

When there is no response to the systemic treatment or if there is an esthetic complaint, lesion sclerosis using certain substances is indicated: 5\% sodium morrhuate, sodium psylliate, $5 \%$ ethanolamine oleate, $1 \%$ polydocanol, sodium tetradecyl sulfate and hypertonic saline. Sclerotic therapy must be reserved for children over 10 years old, at which age hemangioma reaches its maximum stage and tends to regress (13).

Ethanolamine oleate (EO) is an unsaturated acid salt that acts as a sclerosing agent when injected intravenously at up to 15 days after total resolution of the lesion (13). It causes an inflammatory response with the same features as an endothelial fibrosis. The oleic acid portion causes inflammation and activates coagulation by releasing tissue factors and Hangeman factor. Fibrin organization repression occurs due to the action of the ethanolamine portion. This mechanism allows EO to substitute the vascular lesion by a fibrous tissue (13).

Complications of EO intravascular injections include kidney failure and pulmonary embolism, both related to doses higher than $1 \mathrm{~mL}$. Necrosis can occur if the agents are applied into the superficial skin stroma (14).
Lesion recurrence is rare. However, the possibility of including these lesions in the group of true neoplasias due to evidence of invasive growth and recidivism, has been considered. Local recurrence is expected in around one third of the patients with cutaneous hemangioma, but they are less frequent in oral mucosa lesions (15).

Here is reported a case of cavernous hemangioma in the upper lip of a 4-year-old child, which was treated by associating sclerosing agents and surgical excision under general anesthesia.

\section{CASE REPORT}

A4-year-old Caucasian male patient was referred to the service of Oral and Maxillofacial Surgery and Traumatology of our School, with a volume increase in the upper lip. The lesion was harming the patient's social relationships at school, disturbing his routine and compromising his facial esthetics. His mother reported the presence of a red spot in the region at the 6 months of age, which had increased considerably ever since.

Clinically, the lesion was pale red, fluctuant, and had quite elevated areas, mainly in the left side (Fig. 1). The non-pulsatile volume increase was painless and extended over the entire upper lip, changing color under compression (diascopy). Radiographically, there were no alterations and the bone structure of jaws was normal.

Fine needle aspiration biopsy confirmed the diagnosis of hemangioma. The treatment of choice was schlerotherapy with 5\% EO (Ethamolin ${ }^{\circledR}$ injection; 1 $\mathrm{mL}$ ) associated with $5 \mathrm{~mL}$ of $50 \%$ glucose, followed by simple surgical excision. The substances were injected into the hemangioma.

As the patient was a young child and did not cooperate with the applications under local anesthesia, both schlerotherapy and surgery were carried out in a hospital under general anesthesia. Paracetamol (oral suspension; $750 \mathrm{mg}$ ) was prescribed and local ice application was recommended. Three application sessions were undertaken with a 4-month interval between them. After the first period between sessions, the lesion appeared hardened (Fig. 2). Four months after the last session, the lesion was removed by a simple excision (Fig. 3). The lesion appeared fibrotic at that stage, with labial mucosa thickening and atrophic scars, which facilitated the surgical procedure.

One year after treatment, the esthetic result was remarkable (Fig. 4). No lesion recurrence was observed after 2 years of follow up (Fig. 5). 


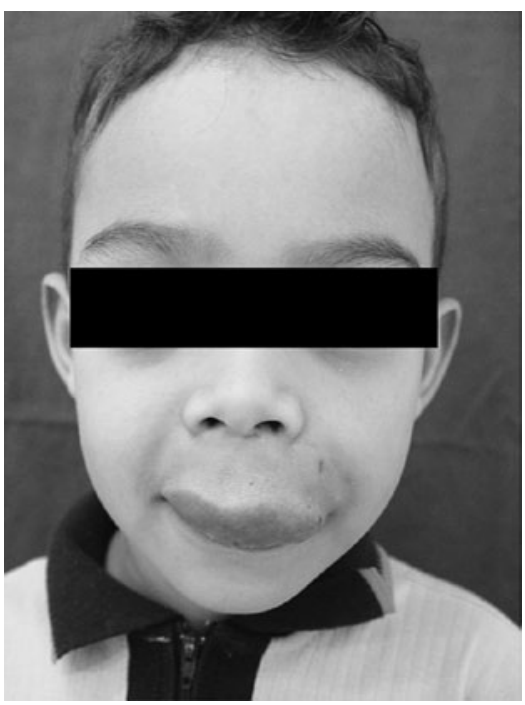

Figure 1. Preoperative frontal views of the patient at the age of 4 with a large hemangioma of the upper lip.

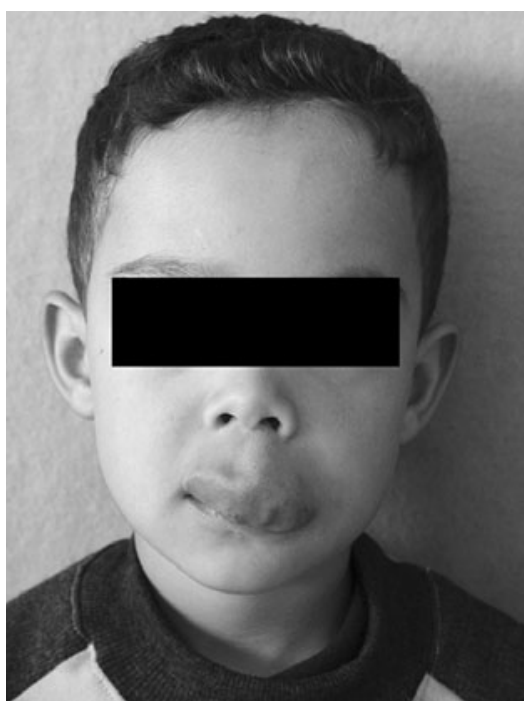

Figure 2. Aspect of the lesion after the first period between EO applications.

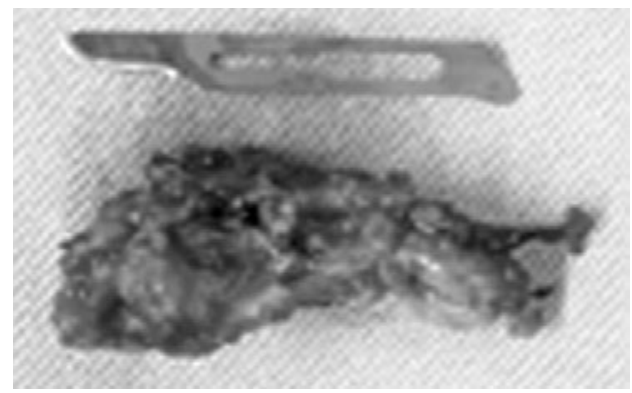

Figure 3. Resection specimen showing fibrotic tissue.

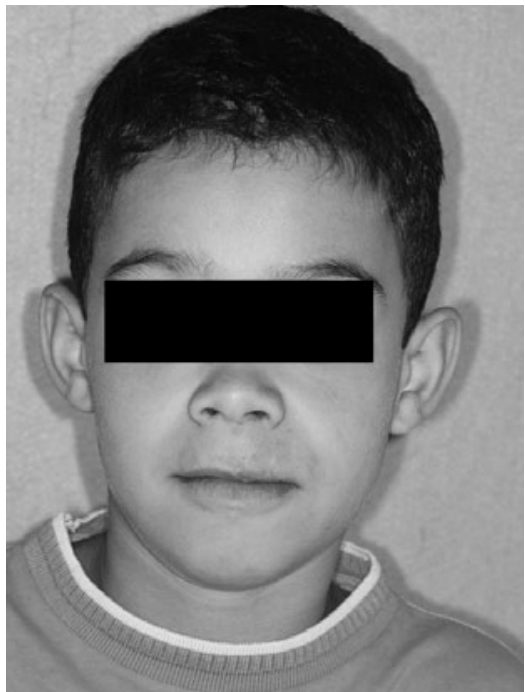

Figure 4. Outcome 1 year after treatment, showing normal lip and an esthetically acceptable appearance.

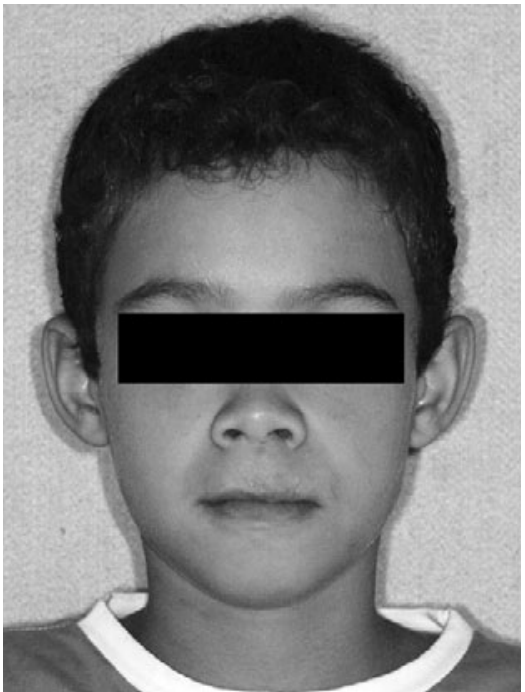

Figure 5. Outcome 2 years after treatment, showing no signs of the hemangioma recurrence. 


\section{DISCUSSION}

Hemangiomas are considered benign tumors of the infancy and childhood, and have a different life cycle, being characterized by 3 stages: endothelial cell proliferation, rapid growth, and, at last, spontaneous involution. They present varied clinical aspects, and can be noted as early as in the 6 month of age as an erythematous spot, reaching great proportions throughout the course of 4 years $(8,12,16)$, as observed in the present clinical case. The lesion affects females in a higher, and the superficial type is the most frequent one (1-3), unlike the present case.

With regard to the location and the number of lesions, a similarity with cases reported in the literature was observed, since approximately $80 \%$ of the patients present a single lesion, and the head and neck region is the most commonly affected (7).

Most infantile hemangioma growth occurs before 5 months of age and the first few weeks to months of life are a critical time for hemangioma growth. Infants with hemangiomas need close observation during this period, and those who need a more specialized care should be referred and seen as early as possible (17).

The proliferation stage is usually expressed up to the first year of age, becoming rather evident in this period (13). In the present case, although the lesion had already been present at 6 months of age, the parents sought treatment for the child only when he was 4 because the size and location of the lesion were causing esthetic and social impairments, as observed in previously reported cases $(2,8)$.

The treatment plan established for hemangiomas must consider aspects such as size, location, length and lesion hemodynamics, patient's age and viability of the technique to be used (16).

Systemic corticosteroid therapy is considered as the most efficient for treating common cutaneous infantile hemangiomas if initiated early in the proliferative phase. Oral prednisone has been used to treat hemangiomas of infancy for 30 years and remains the first-line therapy for difficult hemangiomas. The dosage commonly used is $3-5 \mathrm{mg} / \mathrm{kg}$ per day of oral prednisone between the 1 st and 30th months. The main side-effects of high dose therapy in long-term systemic corticosteroids are cushingoid features, influence on growth, and susceptibility to serious infections, appetite changes, behavior changes, polyuria, thrush, and gastrointestinal discomfort (18).

In the absence of response to the systemic treatment, surgery is indicated for small lesions and for esthetic corrections. It must be preceded by sclerotherapy because endothelial cell fibrosis facilitates lesion removal, thus avoiding hemorrhage risk $(9,14)$, justifying the treatment protocol used in the present clinical case. The association of sclerotherapy and surgery are the most used techniques for the treatment of oral hemangiomas $(13,14)$.

Among the sclerosing agents available, excellent results have been reported for sodium morrhuate, sodium sulfate tetradecyl, polydocanol and ethanolamine oleate, and hypertonic glucose solution $(13,14,19)$. In the present study, the choice for EO associated with glucose was supported by the results in the literature. Baurmash and Mandel (15) reported that sodium morrhuate and sodium sulfate tetradecyl showed higher risks of allergic and anaphylactic responses when compared to EO $(15,20)$. Nishida et al. (10) demonstrated that polydocanol produces fewer effects on the endothelium for the treatment of esophageal varices, justifying thus the use of EO in hemangiomas sclerotherapy (10).

Johann et al. (14) stated that $1 \mathrm{~mL}$ of EO concentration between 1.25 and $2.5 \%$ applied in 3 or 4 sites inside the tumor is considered satisfactory for the treatment of these lesions. In their study, 30 lesions evaluated responded with total clinical resolution. The number of applications required for the treatment of the lesions varies from 1 up to 10 , depending on their size. Lesions up to $20 \mathrm{~mm}$ require fewer applications than those larger than $20 \mathrm{~mm}$. Symptoms often reported after the applications include pain, burning and swelling, within the first $72 \mathrm{~h}(13,14)$. The choice for the solution to be used should be based on the fact that these substances can cause thrombosis when in contact with the superficial vessel inner wall, and a consequent necrosis, interfering thus with the angiogenesis.

Sclerosis protocols described include dosages of $1 \mathrm{~mL}$ of EO in concentrations varying from 1.25 to $5 \%$ delivered in 1 to 10 applications, depending on the lesion dimensions, and maintaining intervals from 7 to 15 days between the applications $(3,13,14)$. The protocol suggested in the present study is in accordance with the dose advocated of $1 \mathrm{~mL}$ in 3 applications. Nevertheless, it differs with regard to the intervals between the sessions. An interval of 4 months was used because of the need of general anesthesia during the applications.

The patient is under a 2 -year postoperative followup showing no signs of hemangioma recurrence, which confirms the low recurrence rates of these lesions (15). 
In this study, the size, location, and systemic conditions allowed establishing the surgical procedures following sclerotherapy, with favorable prognosis and satisfactory healing of the operated area.

In conclusion, sclerosis of large lip hemangioma, associated with surgical excision is a treatment option to be considered as it provides good esthetic and functional outcomes.

\section{RESUMO}

Hemangiomas são tumores benignos da infância que se caracterizam por uma fase de crescimento rápido com proliferação de células endoteliais, ocorrendo em 10 a 12\% das crianças com 1 ano de idade. Sua localização mais comum é nos lábios, na língua, mucosa jugal e no palato. Aproximadamente 50\% dos casos de hemangioma mostram completa resolução e $90 \%$ deles resolvem-se até os 9 anos de idade. As complicações ocorrem em apenas $20 \%$ dos casos e o problema mais comum é a ulceração com ou sem infecção. O tratamento depende da localização, do tamanho e do estágio evolutivo da lesão, bem como da idade do paciente. A cirurgia geralmente é indicada quando não há resposta aos tratamentos sistêmicos ou por razões estéticas, podendo ser empregada sob forma de exérese simples com ou sem plástica. Este artigo apresenta um caso de hemangioma cavernoso labial em uma criança de 4 anos de idade, a qual, devido ao tamanho da lesão, foi submetida a 3 sessões de esclerose vascular seguido de exérese simples da lesão, com acompanhamento clínico de 2 anos de pós-operatório.

\section{REFERENCES}

1. Kin HJ, Colombo M, Frieden IJ. Ulcerated hemangiomas: clinical characteristics and response to therapy. J Am Acad Dermatol 2001; 44:962-972.

2. Bruckner AL, Frieden IJ. Hemangiomas of infancy. J Am Acad Dermatol 2003;48:477-493.

3. Hamlatt A, Adn M, Pasqualini E, Brassier G, Askar B. Pathophysiology of capillary haemangioma growth after birth. Med Hypotheses 2005;64:1093-1096.

4. Drolet BA, Esterly NB, Frieden IJ. Hemangiomas in children. N Engl J Med 1999;341:173-181.

5. Sobrinho FPG, Félix MA, Valle AC, Lessa HA. Hemangioma de úvula: relato de um caso. Rev Bras Otorrinolaringol 2000;69:571574.
6. Frieden IJ. Management of hemangiomas. Special symposium. Ped Dermatol 1997;14:57-83.

7. Mulliken JB, Fishman SJ, Burrows PE. Vascular anomalies. Curr Probl Surg 2000;37:518-584.

8. Esterly NB. Hemangiomas. In: Harper J, Oranje A, Prose N, editors. Textbook of pediatric dermatology. Oxford: Blackwell Science;2000. p. 997-1016.

9. Matsumoto K, Nakanishi H, Koizumi Y, Seike T, Kanda I, Kubo Y. Sclerotherapy of hemangioma with late involution. Dermatologic Surgery 2003;29:668-671.

10. Nishida R, Inoue R, Takimoto Y, Kita T. A sclerosant with astringent properties developed in China for oesophageal varices: comparason with ethanolamine oleate and polidocanol. J Gastroenteral Hepatol 1999;14:481-488.

11. Eichenfield LF. Evolving knowledge of hemangiomas and vascular malformations. Arch Dermatol 1998;134:740-742.

12. Dourmishev LA, Dourmishev AL. Craniofacial cavernous hemangioma: successful treatment with methylprednisolone. Acta Dermatoven APA 2005;14:49-52.

13. Marchuk DA. Pathogenesis of hemangioma. J Clin Invest 2001;107:665-666.

14. Johann ACBR, Aguiar MCF, Carmo MAV, Gomez RS, Castro WH, Mesquita RA. Sclerotherapy of begin oral vascular lesion with ethanolamine oleate: an open clinical trial with 30 lesions. Oral Surg Med Pathol Oral Radiol Endod 2005;100:579-584.

15. Baurmash $\mathrm{H}$, Mandel L. The nonsurgical treatment of hemangioma with sotradecol. Oral Surg Oral Med Oral Pathol 1963;16:777-782.

16. Zhao Y, Glesne D, Huberman E. A human peripheral blood monocyte - derived subset acts as pluripotent stem cells. Proc Nati Acad Sci USA 2003;100:2426-2431.

17. Linda C, Chang LC, Haggstrom AN, Drolet BA, Baselga E, Chamlin SL, et al.. Growth characteristics of infantile hemangiomas: implications for management. Pediatrics 2008;122:360-367.

18. Zhou Q, Yang XJ, Zheng JW, Wang YA, Zhang ZY. Short-term high-dose oral prednisone on alternate days is safe and effective for treatment of infantile hemangiomas. J Oral Maxillofac Surg 2010;109:166-167.

19. Un ZJ, Zhang L, Zhanh WF, Alsharif MJ, Chen XM, Zhao YF. Epithelioid hemangioma in the oral mucosa: a clinicopathological study of seven cases and review of the literature. Oral Oncology 2006; $42: 441-447$.

20. Childers ELB, Furlong MA, Fanburg-Smith JC. Hemangioma of the salivary gland: a study of ten cases of a rarely biopsied/excised lesion. Annals of Diagnostic Pathology 2002;6:339-344.

Accepted September 9, 2010 